\title{
Conceptual evolution of the bioeconomy: a bibliometric analysis
}

\author{
Benoit Mougenot $^{1}$ (D) Jean-Pierre Doussoulin ${ }^{2,3}$ (D)
}

Received: 21 January 2021 / Accepted: 28 April 2021 / Published online: 5 May 2021

(c) The Author(s), under exclusive licence to Springer Nature B.V. 2021

\begin{abstract}
The growing concern over the change in climatic conditions and the management and conservation of biological resources makes it necessary to create models suitable for the sustainable management of these resources. The bioeconomy suggests a model based on the production of renewable biological resources and the conversion of these resources into value-added products. The main aim of this article is to assess the impact of the bioeconomy on the scholar. This manuscript also aims to continue and update this discussion of public policies oriented toward a bioeconomy. This research follows a computed analysis based on the R package using Biblioshiny, a web interface for Bibliometrix analysis; this approach offers a positive alternative for studying bioeconomic literature in the traditional bibliometric analysis. This is one of the first research which analyzes the literature pathways of the bioeconomy issue using a computational analysis. Our article concludes that the principles of the bioeconomy have a strong potential to address these related challenges to manage and maintain the environment.
\end{abstract}

Keywords Bioeconomics · Bibliometric analysis · Environment

\section{Introduction}

The way in which the world responds to tackle the coronavirus could be an exemplary lesson in the fight against climate change. The outbreak of the coronavirus is causing an unprecedented health, economic and environmental crisis for the world, the consequences of which still elude us (Doussoulin, 2020). As a result, the bioeconomy can contribute to these three main domains in the following ways. First, related to health and pharmaceutical industries, the change includes the way cancer treatments are delivered and improving the management of infectious diseases (Haines, 2021; Mittra, 2015). Second, the bioeconomy has gained prominence on the economic agenda in recent years. For example, in

Benoit Mougenot

bmougenot@usil.edu.pe

1 Facultad de Ciencias Empresariales, Universidad San Ignacio de Loyola, Lima, Peru

2 Economic Institute, Universidad Austral de Chile, Valdivia, Chile

3 Research Team on the Use of Panel Data in Economics, Université Gustave Eiffel, Champs-sur-Marne, France 
2012, the US government proposed a report titled National Bioeconomy Blueprint, which stated that this type of activity has grown by $10 \%$ annually over the previous decade (Carlson, 2016; White House, 2012). The European Union has developed a bioeconomy strategy that promotes economic policies that create value and jobs worth around 2 billion euros, which is equivalent to 9\% of Europe's active population. (European Commission, 2012; McCormick \& Kautto, 2013). Brazil, Russia, India, China, and South Africa (BRICS), as well as other African countries, have incorporated this new economic development based on bioeconomy-based strategies in energy production, agriculture, and biomass (Bambo \& Pouris, 2020; Louvel \& de Gromard, 2017; Virgin \& Morris, 2016). Finally, bioeconomy can provide a new way to improve international cooperation in the direction of biodiplomacy (Aguilar \& Patermann, 2020). It is crucial to consider the dangers of justifying the bioeconomy on the basis of climate change and biodiplomacy, which could lead to a shift away from native crops and forests in favor of more useful and profitable crops for energy and biomass production. (Van Renssen, 2014).

On how to assess the importance of these issues on the global public agenda, Li and Zhao (2015) studied the literature in terms of trends of environmental conservation from an analysis of 113,468 publications from the past 20 years. Schaltegger et al. (2013) used a database containing 814 articles to analyze the bibliometric trend on environmental management accounting (EMA), showing that EMA was at first, a young discipline. Mao et al. (2018) using the Web of Science Core Collection performing a bibliometric analysis of 9514 literature report to assess the relationship between biomass energy and the environment. Ruiz-Real et al. (2018) argued for a notable increase in the circular economy analyzing 743 articles during the period 2006-2017. Bugge et al. (2016) performed a bibliometric literature indexed analysis of 453 articles from 2005 to 2014 concluding that the importance of bioeconomy had increased. Other authors have looked into the effects of COVID-19 on the issues mentioned above using a more global bibliometric approach (Chahrour et al., 2020; Doussoulin \& Mougenot, 2021; Zhai et al., 2020).

The aim of the bioeconomy is to build an economy based on the consumption and production of goods and services from the direct use of biological resources and its sustainable transformation (European Commission, 2018). The increased demand for sustainable production using biological material justifies the need for updated research and policies in Europe, USA, and Latin-American countries emphasizing on the bioeconomy (Devaney \& Iles, 2019; McCormick \& Kautto, 2013; Trigo et al., 2015). The demonstration issues in major countries can be illustrated as follows (see Table 1).

The definition of bioeconomy and bio-based economy has evolved over time (Birch \& Tyfield, 2013; Staffas et al., 2013) and recent research has characterized the bioeconomy as a polysemous term including three main trajectories with its own dynamics (Giampietro, 2019; Vivien et al., 2019).

The first is developed from an ecological economic perspective (Georgescu-Roegen, 1971). The innovations and knowledge are built to include the limits on the natural environment anchored in a given territory, for example, through agro-ecological practices and socio-technical agreements (Schmidt et al., 2012). The second is developed into a green growth perspective, supported by the OECD, multinationals and start-ups and based on the development of biotechnology (Organisation for Economic Cooperation and Development (OECD), 2009). Therefore, biological organisms are at the service of the economy. The knowledge is protected mainly by patents and companies benefit from it. The third is based on innovations which replace our dependence on oil resources, through the exploitation of biomass, for example, with the development of Biorefineries and small-scale methanizers to produce energy (European Commission, 2018). 


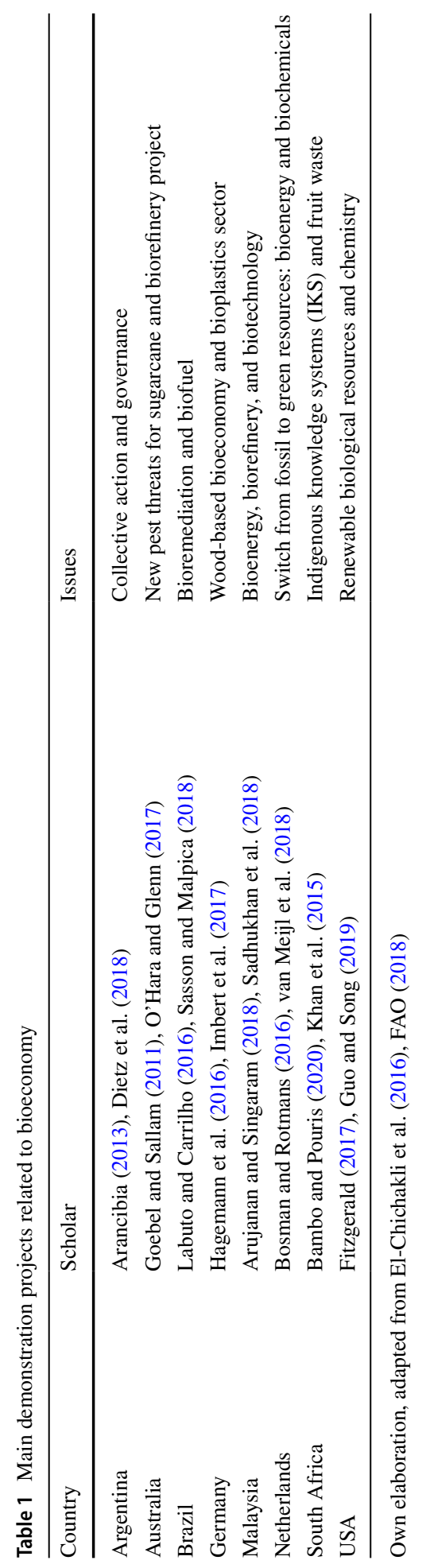


The processes that constitute the bioeconomy can be systematized using their inputs, the processes of product creation and the outputs created. The processes are gaining in added value as inputs are transformed into products. Figure 1 shows a summary table of these elements (Bosman \& Rotmans, 2016).

In this context, this article aims at analyzing the impact of the bioeconomy on scientists from 1999 to 2018. Promoting a bioeconomy path that could help countries limit their level of environmental pollution. The research of the transition toward a bioeconomy and the opportunities for its political implementation were part of the challenges partially worked on but not finished in the article of Bugge et al. (2016). This manuscript also aims to continue and update this discussion of public policies oriented toward a bioeconomy.

The importance of this study concerns the first bibliometric research that analyzes the literature pathways of the bioeconomy issue using Biblioshiny a web interface for bibliometrix analysis based in R package (Gagolewski, 2011; Moral-Muñoz et al., 2020; Saikia et al., 2020).

The increased demand for bioeconomy issues justifies the need for more effective economic policies with a focus on sustainability.

The article is structured as follows: Sect. 2 outlines a bibliometric analysis of peer-reviewed articles on the topic. Section 3 identifies central organizations, country, and scientific collaborations and one of the main results is that the bioeconomy concept has been considered

\section{Added Value}
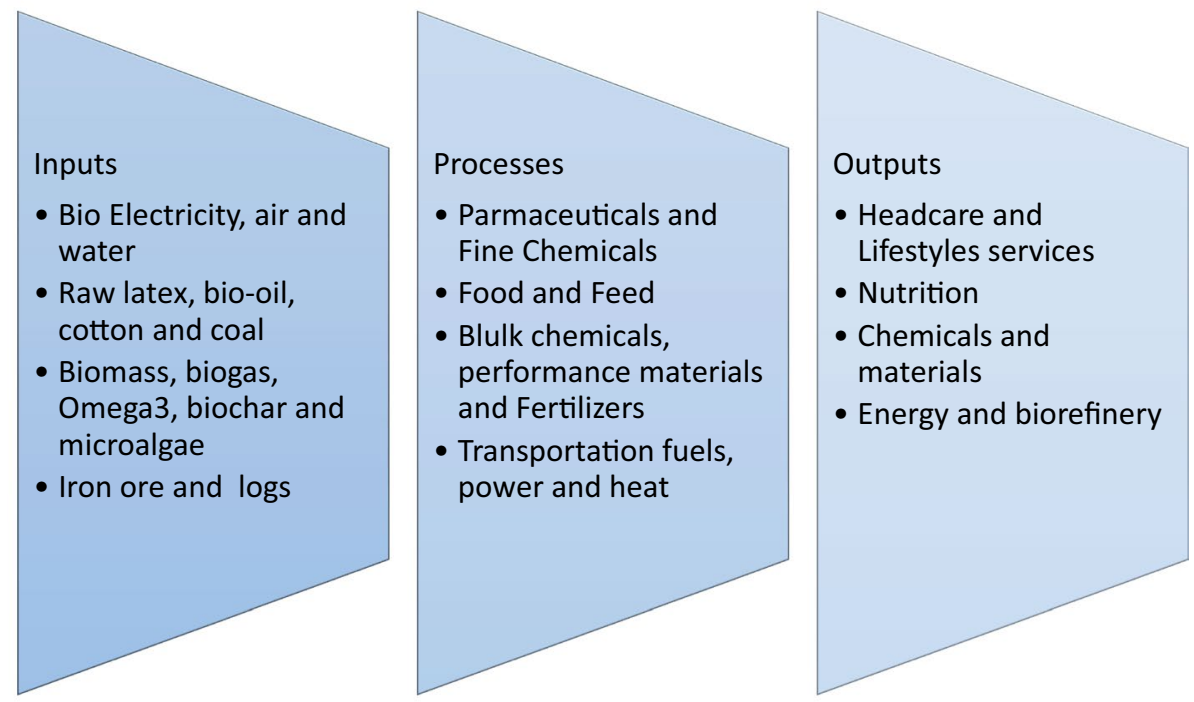

Own elaboration, adapted from Bosman and Rotmans (2016).

Fig. 1 Bioeconomy processes systematized 
from many scientific fields. Section 4 concludes and proposes limitations and a future research direction.

\section{Materials and methods}

This section describes the data sources and the research method used to identify and analyze the study.

\subsection{Data sources and collection}

This article selects the Scopus collection as the data source (https://www.scopus.com/). Scopus is actually the world largest abstract and citations database with more than 81 million items from more than 7000 publishers in 105 countries and includes 17 million author profiles (Elsevier, 2021). The entered search terms are [Bioeconomy OR Bio-economy OR Biobased economy OR Bio-industries OR Bioinnovation]. The analyzed period was from 1999 to 2018, which corresponds to the publication of the European Commission's updated bioeconomy strategy (2018). The search language is all languages. The Scopus bibliographic citation database includes various types of documents, but only original articles were considered in the present analysis. A total of 1732 documents were finally selected for the analysis. The complete records for each publication retrieved during the search were converted as a Scopus BibTex file and imported into Bibliometrix and Biblioshiny.

\subsection{Research method}

\subsubsection{Research software}

Bibliometrix and Biblioshiny open source packages are used from the R language environment. Bibliometrix allows completing the full process of scientific literature analysis and data process. Biblioshiny captures the core Bibliometrix code and creates an online data analysis framework (Aria \& Cuccurullo, 2017). Biblioshiny enables users to perform pertinent bibliometric and visual analysis based on an interactive web interface.

\subsubsection{Network analysis and mapping}

Using the Bibliometrix and the Biblioshiny packages, the research allows showing bibliometric indicators on bioeconomy such as publication volume in number of articles, citation count, and keywords. Then, the article presents figures and maps such as a citation network diagram, thematic evolution map, and an international collaboration network map to identify research hot spots, research status, and the dynamics of bioeconomy frontier in different periods (Fig. 2). 


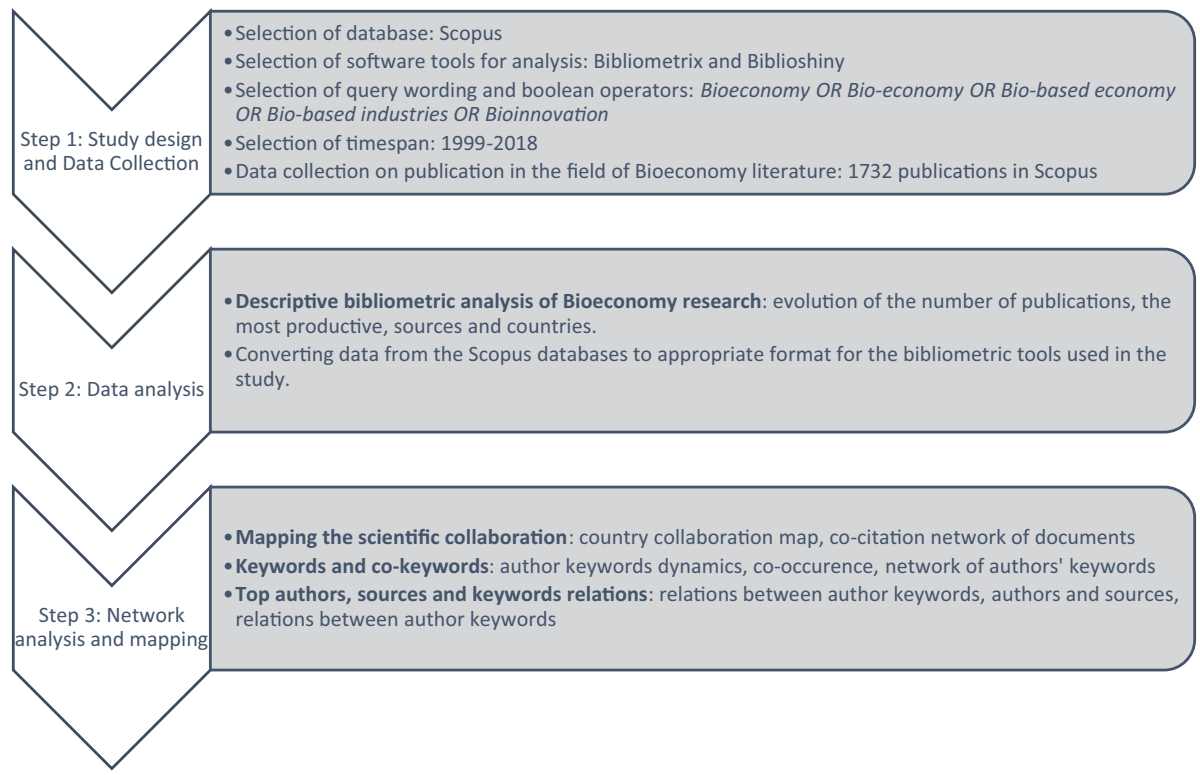

Fig. 2 Research methodology

\section{Results and discussion}

\subsection{Evolution of the number of articles}

The evolution of the number of articles published on bioeconomy during the period 1999-2018 is presented in Fig. 3. The number of publications started to increase in 2005 (14 documents) and considerably increased over the period analyzed. The graph shows an escalation in bioeconomy publications from 1 document in 1999 to 386 in 2018, spotted as the peak of publication. Both the terms bioeconomy and bio-based economy seem to have

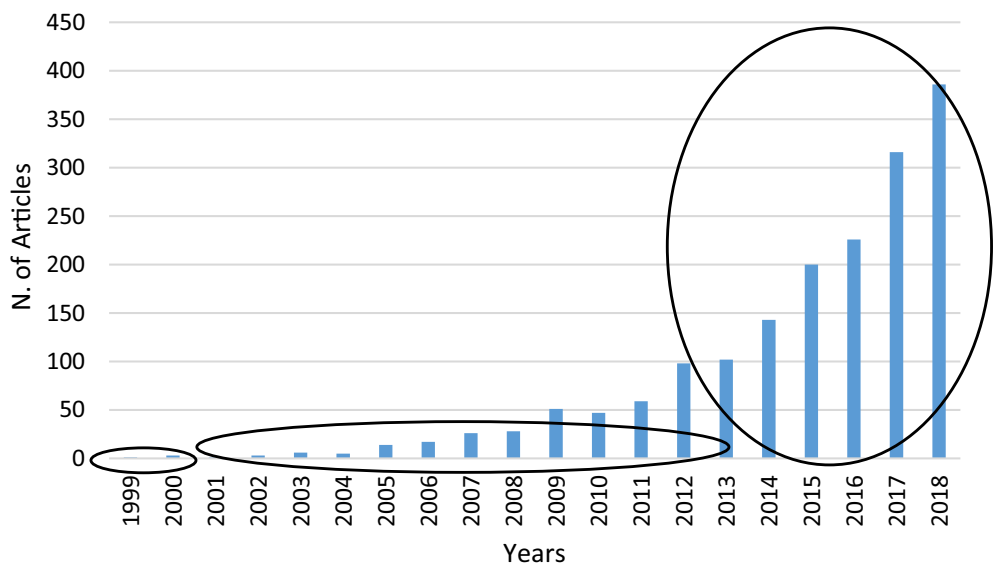

Fig. 3 Evolution of the number of articles (1999-2018). Source: Scopus/Biblioshiny 
already been used in the early 2000s, according to the objectives of the Lisbon agenda in 2002. However, the European Commission in the mid-2000s introduced the bioeconomy into policy discussions (McCormick \& Kautto, 2013). Previous studies have shown that since 2005 , the number of citations and the number of articles related to the bioeconomy started to increase rapidly (Bugge et al., 2016; Staffas et al., 2013). Since 2013, various countries have included policies aimed at boosting the bioeconomy and this is demonstrated by publications (Rodríguez et al., 2017).

The journal that published most articles about bioeconomy over the period 1999-2018 is presented in Fig. 4. "Journal of Cleaner Production" was the journal that published the highest number of articles on bioeconomy (93) during the period 1999-2018. "Biofuels Bioproducts and Biorefining" was the second leading journal with 68 articles found on bioeconomy. The journal "Sustainability" published 43 articles, meanwhile the journal "Industrial Crops and Products" published 34 articles. In addition, "Journal of Cleaner Production" and "Biofuels Bioproducts and Biorefining" are the sources with the higher impact, with a h_index of 28 and 23, respectively.

\subsection{Mapping the scientific collaboration}

Table 2 shows countries with higher scientific production on bioeconomy. We observed 2 American countries (USA, Canada), 1 Asian Country (China), and 7 European countries (Germany, Italy, UK, Netherlands, France, Spain, and Finland) among the top 10 countries. Developed countries occupy a higher proportion and present a strong research impact in the field of Bioeconomy. The publication of the Organisation for Economic

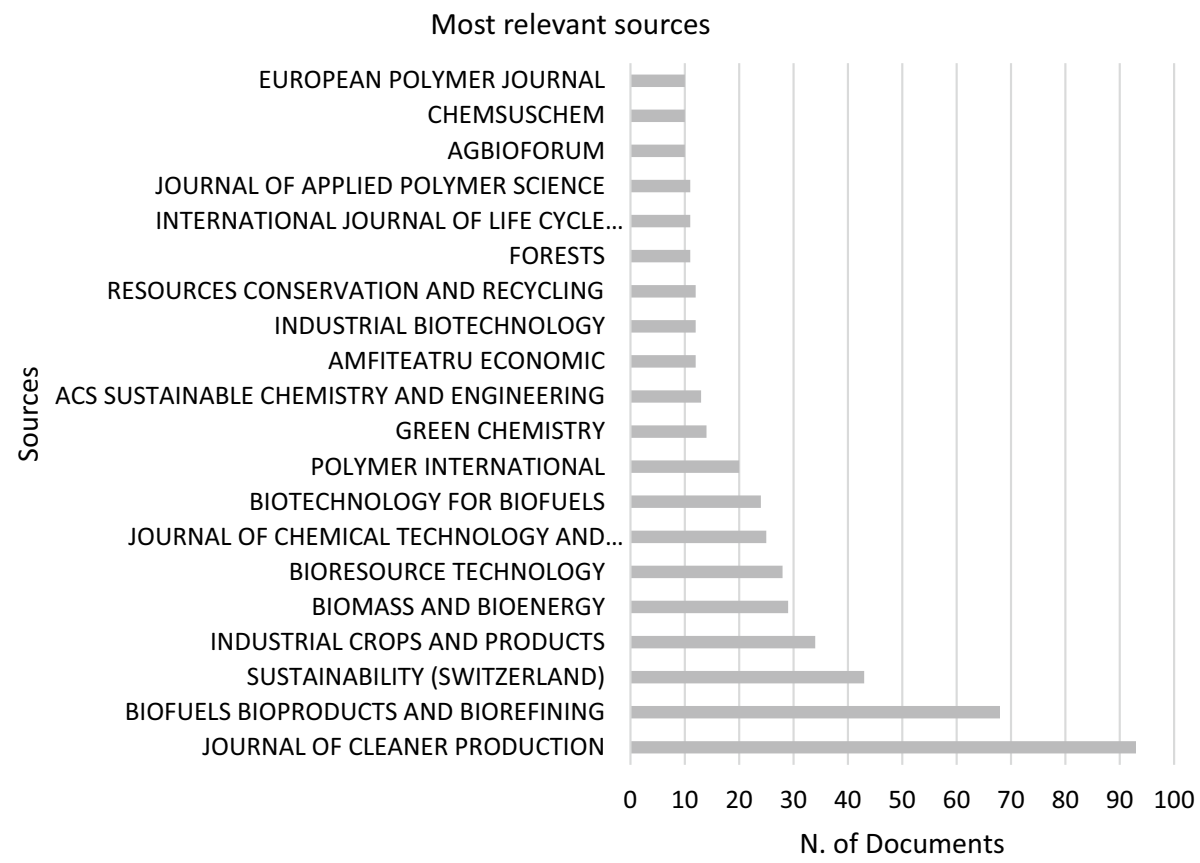

Fig. 4 Most relevant sources in the field of Bioeconomy. Source: Scopus/Biblioshiny 
Table 2 Scientific production of the main countries linked to the bioeconomy (1999-2018). Source: Scopus/Biblioshiny

\begin{tabular}{llcc}
\hline Countries & Articles & Total citation & $\begin{array}{l}\text { Average } \\
\text { article cita- } \\
\text { tion }\end{array}$ \\
\hline USA & 568 & 7851 & 13.82 \\
Germany & 313 & 2783 & 8.89 \\
UK & 222 & 2109 & 9.50 \\
Netherlands & 215 & 2684 & 12.48 \\
China & 206 & 939 & 4.56 \\
France & 180 & 932 & 5.18 \\
Spain & 153 & 1103 & 7.21 \\
Canada & 150 & 1242 & 8.28 \\
Finland & 138 & 937 & 6.79 \\
\hline
\end{tabular}

Cooperation and Development (OECD) document, entitled "The Bioeconomy to 2030: Designing a Policy Agenda" (Organisation for Economic Cooperation and Development (OECD), 2009, p. 20) is one of the first documents to oriented national bioeconomy strategies and policies (Staffas et al., 2013).

The USA obtained the first position in the world with a total of 568 articles published. The papers published in the USA were cited 7851 times. In 2012, the country published the National Bioeconomy Blueprint, a plan document to reinforce its activities around the bioeconomy and bio-based products (McCormick \& Kautto, 2013). The rest of top five with the largest number of publications is composed by European countries, Germany (313 articles), Italy (240 articles), UK (222 articles), and Netherland (215 articles). In early 2012, the European Commission published a strategic and action plan document (European Commission, 2012). The main objective was to improve the knowledge-base for the bioeconomy, based on innovation to improve the sustainable productivity of natural resource and promote the development of production systems that reduce the climate change impacts. The document was updated and reinforced in 2018 (European Commission, 2018).

China has published 206 articles in the field of Bioeconomy during the studied period. Nevertheless, the impact of Chinese paper could be improved, because we observe a low frequency of citation (4.56). However, China is pursuing a strong position in the bioeconomy field with a special interest on biochemistry and life sciences (Staffas et al., 2013). In addition, main affiliations with higher production are available in "Appendix 1."

A map shown in Fig. 5 identifies the country collaboration of the main producing countries. Two countries hold a connection line indicating the status of collaboration among them. The scale of cooperation is represented through the thickness of the line. The USA, China, and Western European countries showed deepened cooperation and exchange among scholars. Bugge et al. (2016) observed that different kinds of organizations such as companies and not only universities were placed in a geographic cluster of collaborations.

Figure 6 shows a co-citation analysis, with each box representing an article in the bioeconomic literature. The size of the box indicates the volume of the citation (the larger the box, the more author's documents are cited) and the proximity of the boxes indicates a close relationship between the co-cited documents. As a result, the formation of co-citation networks around the authors mentioned above is evident. 


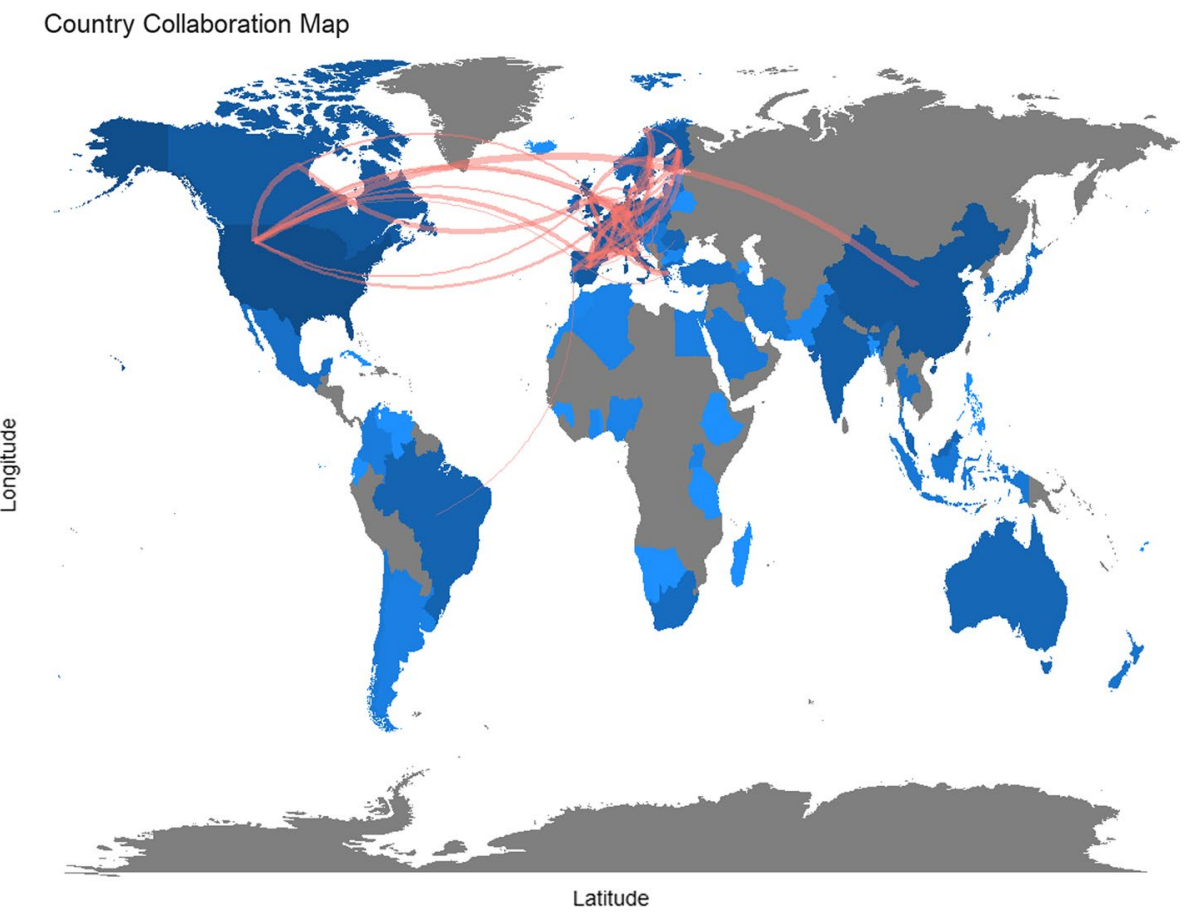

Fig. 5 Country collaboration map. Source: Scopus/Biblioshiny

\subsection{Analysis of keywords and co-keywords}

The main-term occurrences per year are presented in Fig. 7. Most of them have increased over time. However, some terms have experienced a more dynamic growth compared to others. During the studied period, the terms with the highest increase in occurrences were mainly "bioeconomy" which is driven by the 2013 policies proposed in countries like Germany, Spain, and Finland (Rodríguez et al., 2017); then, at a lower level, "sustainability," "bio-economy," "biomass," "biorefinery" and "bioenergy." To complete, "Appendix 2" shows the evolution of trend topics related to different fields of the bioeconomy. This significant increase in the term bioeconomy is driven by policies proposed in countries such as Germany, Spain, and Finland.

Figure 8 shows the keyword co-occurrence network. The number of occurrences of the keywords is represented through the dimension of the box. More co-selected authors' keywords in the bioeconomy literature increase the size of the box. The topic similarity and its relative strength are represented through the distance between the elements of individual pairs. Different box colors were assigned to individual clusters. A network of 5 distinct clusters is highlighted in Fig. 7, representing individual subfields in bioeconomy research. 


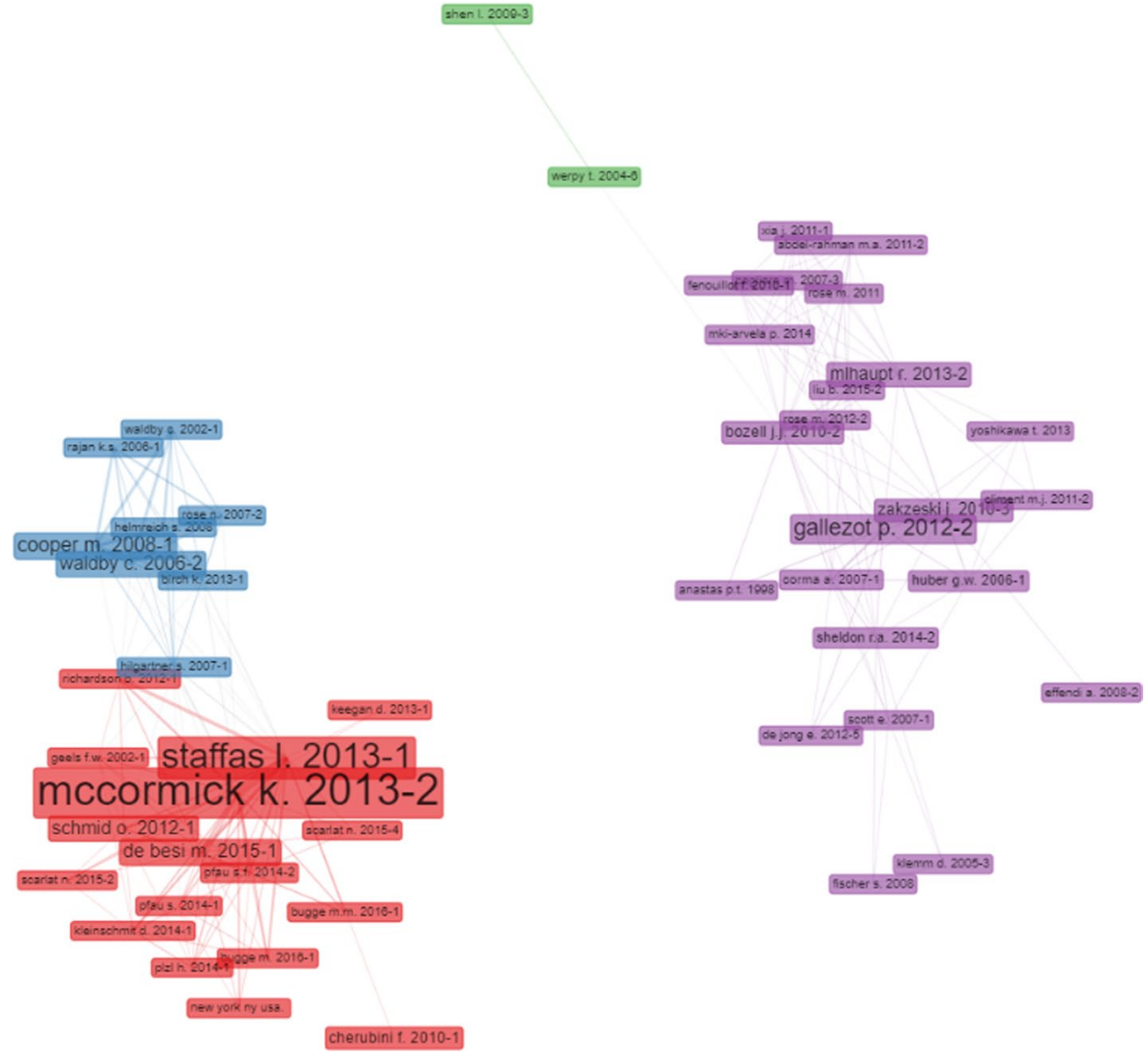

Fig. 6 Co-citation network. Source: Scopus/Biblioshiny

\subsection{Keywords, top authors, and sources relations}

In Fig. 9, a three-field graph represented the relationships between the keywords, the main authors' keywords, and the sources. Therefore, the diagram by rectangles with distinct colors illustrated the main elements. The value of the sum of the relations appearing between the element represented by the rectangles and the diagram of the other elements designed the height of the rectangles. The size of the rectangles depends on more relations the element had.

The analysis showed in which research topics of the bioeconomy concept the authors of bioeconomy publications had explored and which sources they had most often published. The research topics were considered here as the keywords of the authors. The analysis of keywords, top authors, and sources indicated that four authors (i.e., Sanders JPM, Patel MK, and Birch K) and five sources (i.e., Journal of Cleaner Production, Biofuels, Bioproducts and Biorefining; Industrial; Industrial Biotechnology, Journal of Chemical Technology and Biotechnology and Sustainability) were closely linked to the main research topics of bioeconomy ("bioeconomy," "biorefinery," "bio-based economy" and "biomass"). 


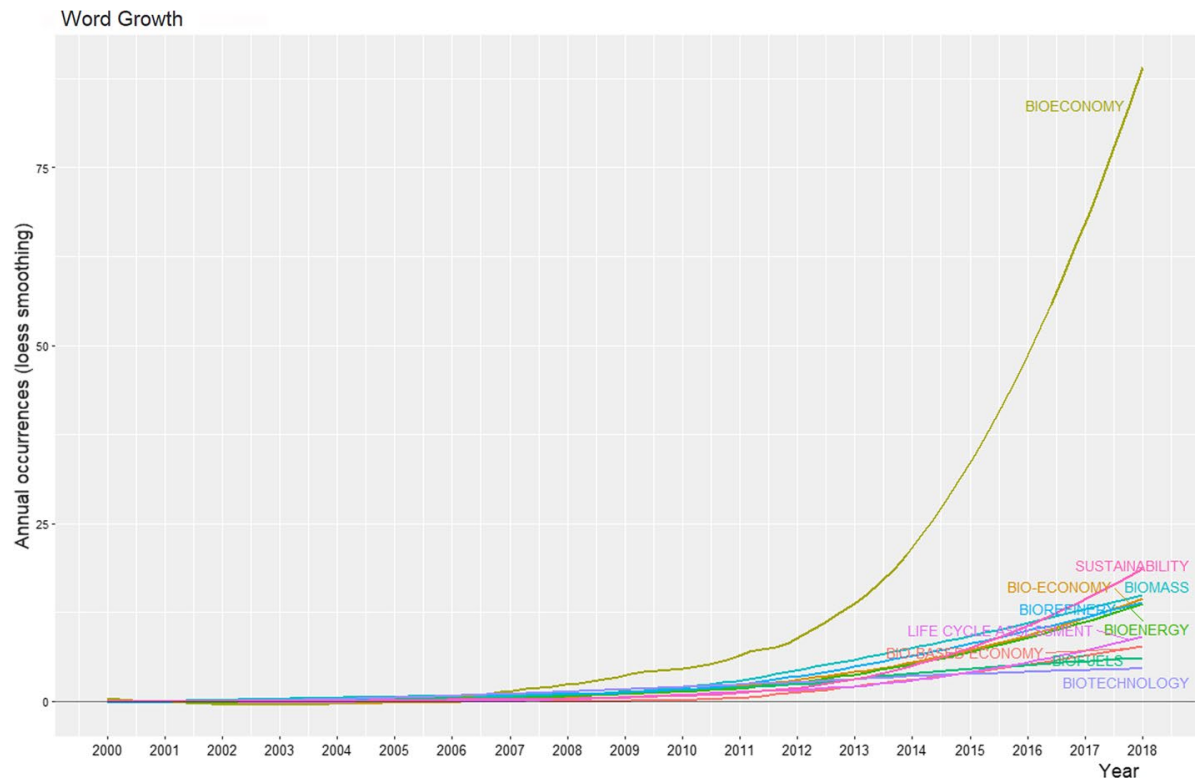

Fig. 7 Evolution of authors' keywords in the bioeconomy literature. Source: Scopus/Biblioshiny

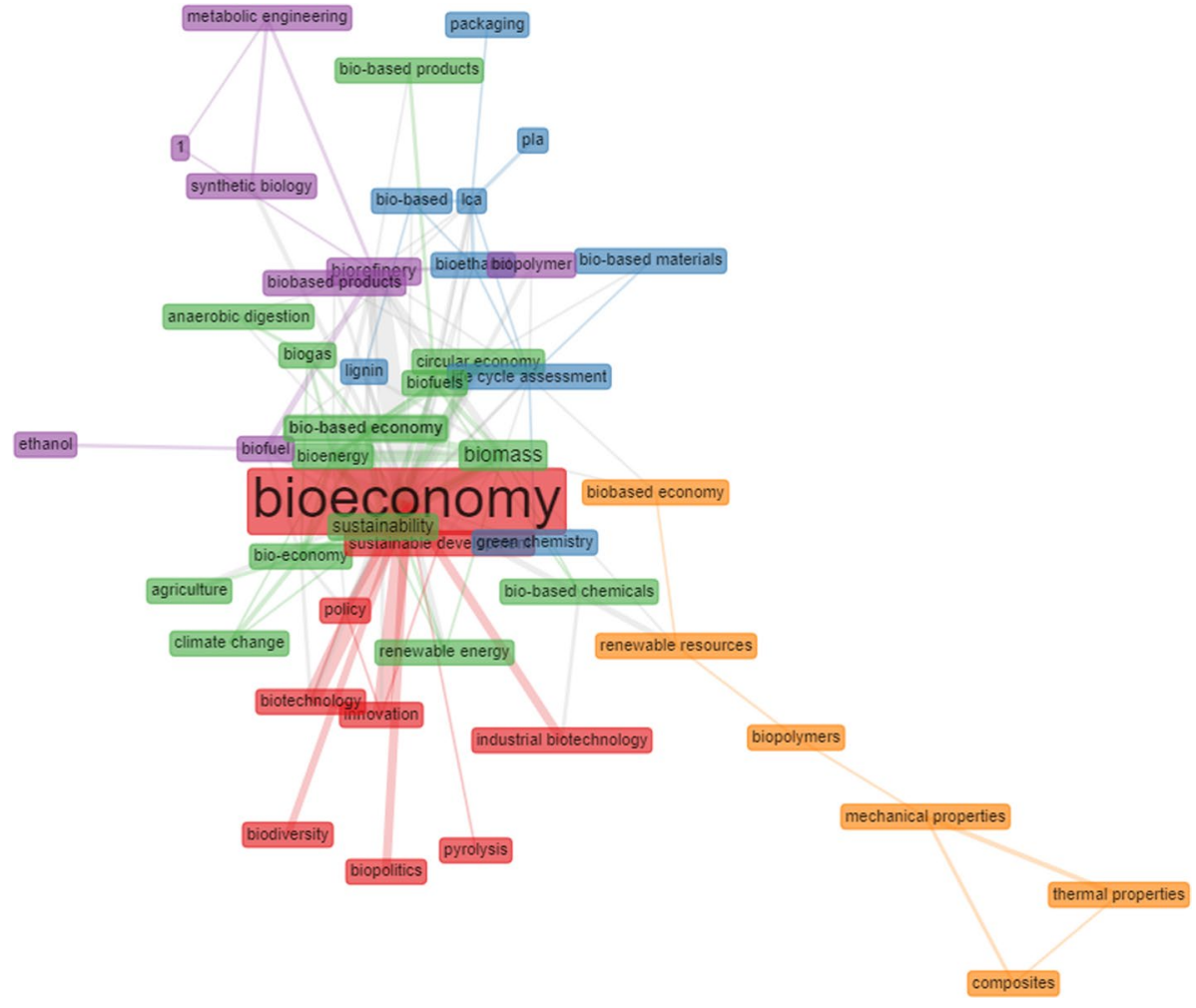

Fig. 8 Author keywords co-occurrence network in the bioeconomy literature. Source: Scopus/Biblioshiny 


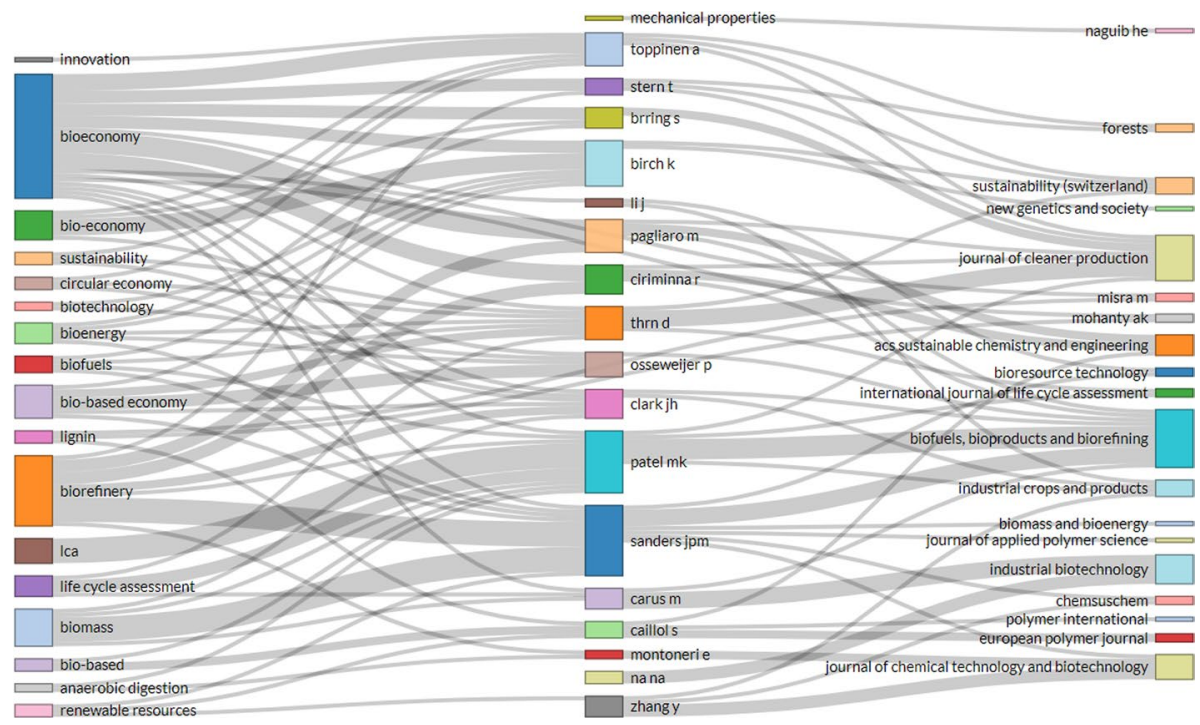

Fig. 9 Relationships between author keywords (left), authors (middle), and source (right). Source: Scopus/ Biblioshiny

\section{Conclusions}

We can note the growing interest, scientific and public cooperation in bioeconomy-related fields during the analyzed period. This trend has increased over the past two decades, but there has been relatively little effort to conduct a systematic review of the thematic and methodological trends that create the intellectual structure of the bioeconomy. This article has been oriented to face this challenge of systematizing and analyzing the Scopus database.

In light of an exploratory writing review, this article reported on the evolution of the number of articles, the most relevant sources, the science output of main countries and their collaboration, the co-citation network and the evolution of author keywords and the reach of the idea of the bioeconomy.

While advances in environmental bibliometric research are often seen as performing a critical function by focusing on important and contemporary issues, for instance, environmental conservation, environmental management accounting, biomass energy and the environment, the article has indicated that the bioeconomy establishes a useful examination field; despite the fact that everything considered, the examination analyzed in this survey has probably been engaged in related fields previously, or in a comparative exploration under various headings, for example, the sustainable production and consumption. The paper outlined how a scope of various subjects is engaged in creating information that supports the rise of the bioeconomy after 1999.

The research of the opportunities for the implementation of bioeconomy policies in the various countries was part of the challenges addressed in this article.

The bibliometric research of bioeconomy research documents collected from the Scopus database. The most common language for the document is English (1732 documents). The first record on bioeconomy appeared in 1979 (Ikeda, 1979), but it was only after 2000 that 
the concept attracted researchers and since then the number of publications in this field has increased to 1732 documents published between 1999 and 2018. The country that has done much of the bioeconomy research is the USA (568 publications, 7851 citations, and 13.82 average article citations). Regarding this topic, it is important to mention the extensive cooperation and exchanges among scholars from the USA, China, and Western Europe.

The journal which published the most on bioeconomy research is the "Journal of Cleaner Production" (93 articles), which has had an impact factor of 7246 as of November 2020. Other important sources were biofuels, bioproducts, and biorefining; Industrial Biotechnology, Journal of Chemical Technology and Biotechnology and Sustainability, with this, perhaps the writing survey should be expected to recognize top three reviews on the Bioeconomy issue with more than 40 articles published.

The most productive bioeconomics authors are Patel, M. K. (10 documents), Birch, K. (8 documents) and Sanders J.P.M (5 documents) and the co-citation network of references revealed four clusters; "bioeconomy," "biorefinery," bioeconomy" and "biomass."

Finally, the results obtained in this article suggest that the literature on the bioeconomy represents one of the keys to sustainable development in the world, especially in developing countries for the years to come.

\subsection{Limitations and future direction of research}

Our examination has some limitations. One of the restrictions is the use of the Scopus information base. Although the WoS information base is extremely extensive and legitimate, it is smarter to use different datasets including WoS, Google Scholar, Latindex, or HAL (open archive) allowing examination in other languages like Spanish and French. Another difficulty we faced was that the most prominent and influential authors were organized according to the number of publications; therefore, publications with a single document but with many citations may be misrepresented in the results.

Given the main emphasis on the sciences which make up the core of bioeconomy research, an important point for future examinations is the association between the bioeconomy and its broader cultural ramifications, such as toward economics. In addition, the rise of a bioeconomy is necessary to infer the use and use of conventional biotechnologies in a few different fields and spaces. This may even include the study of new materials that allow to face the medical challenges of the COVID-19 crisis. Consequently, further researches on the state of the bioeconomy can not only allow scientific advances, but also progress while taking into account economic, environmental, and public health challenges at local and regional scales.

\section{Appendix 1}

See Table 3. 
Table 3 The 10 most prominent organizations in terms of number of published papers

\begin{tabular}{lll}
\hline Affiliations & Countries & Articles \\
\hline Iowa State University & USA & 34 \\
Ghent University & Belgium & 31 \\
Wageningen University & Netherlands & 29 \\
Utrecht University & Netherlands & 26 \\
Delft University of Technology & Netherlands & 23 \\
Lund University & Sweden & 23 \\
University of Helsinki & Finland & 20 \\
University of Toronto & Canada & 18 \\
University of California & USA & 17 \\
University of Eastern Finland & Finland & 17 \\
\hline
\end{tabular}

\section{Appendix 2}

See Fig. 10.

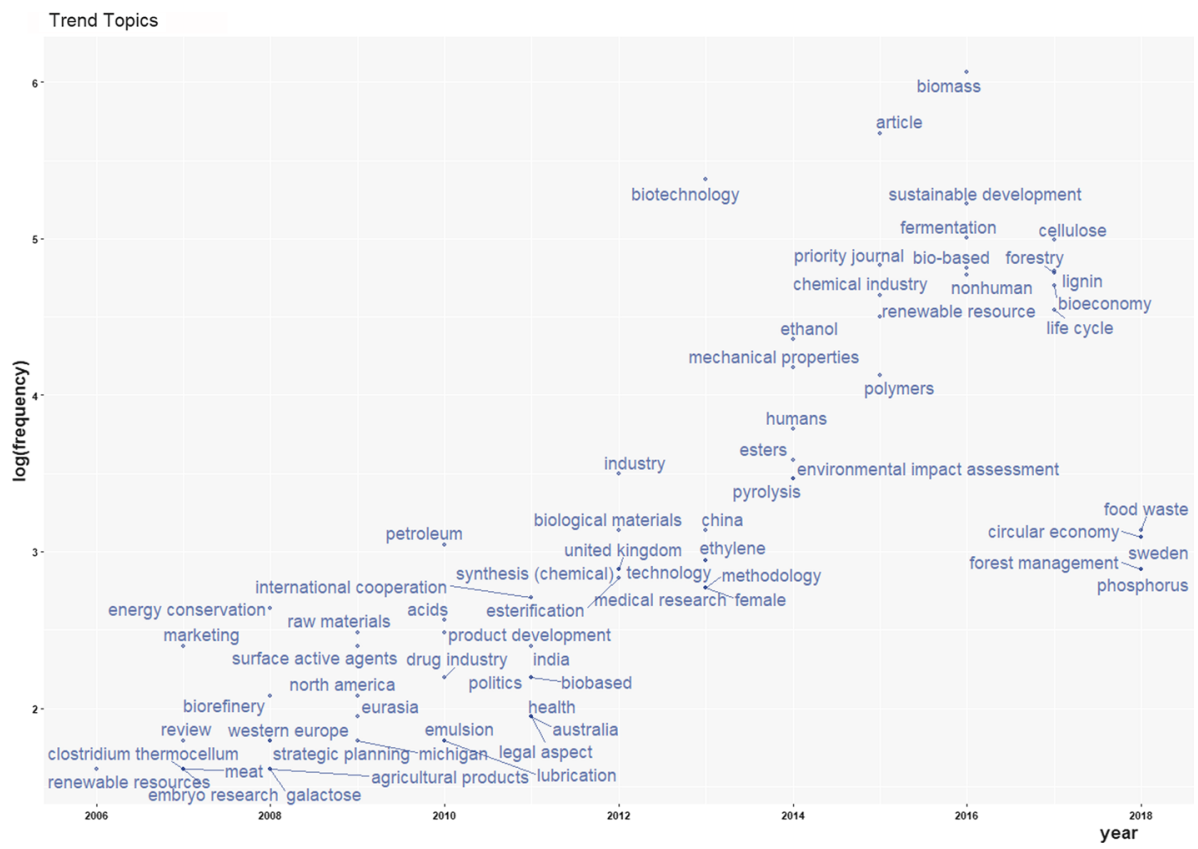

Fig. 10 Evolution of trend topics 
Acknowledgements The authors would like to acknowledge and extend their gratitude to the Universidad San Ignacio de Loyola and the Universidad Austral de Chile for providing the means and facilities for research.

Author contributions BM and JPD contributed to conceptualization, validation, investigation, writingoriginal draft preparation, and writing - review and editing; BM contributed to methodology, software, formal analysis, and data curation. All authors have read and agreed to the published version of the manuscript.

Funding This research received no external funding.

Data availability Data supporting reported results can be found in Scopus https://www. scopus.com/.

Code availability Results are obtained using Biblioshiny, a web interface for Bibliometrix analysis.

\section{Declarations}

Conflict of interest The authors declare no conflict of interest or competing interest.

\section{References}

Aguilar, A., \& Patermann, C. (2020). Biodiplomacy, the new frontier for bioeconomy. New Biotechnology, $59,20-25$.

Arancibia, F. (2013). Challenging the bioeconomy: The dynamics of collective action in Argentina. Technology in Society, 35(2), 79-92.

Aria, M., \& Cuccurullo, C. (2017). Bibliometrix: An R-tool for comprehensive science mapping analysis. Journal of Informetrics, 11(4), 959-975.

Arujanan, M., \& Singaram, M. (2018). The biotechnology and bioeconomy landscape in Malaysia. New Biotechnology, 40, 52-59.

Bambo, T. L., \& Pouris, A. (2020). Bibliometric analysis of bioeconomy research in South Africa. Scientometrics, 125(1), 29-51.

Birch, K., \& Tyfield, D. (2013). Theorizing the bioeconomy: Biovalue, biocapital, bioeconomics or... what? Science, Technology, \& Human Values, 38(3), 299-327.

Bosman, R., \& Rotmans, J. (2016). Transition governance towards a bioeconomy: A comparison of Finland and The Netherlands. Sustainability, 8(10), 1017.

Bugge, M. M., Hansen, T., \& Klitkou, A. (2016). What is the bioeconomy? A review of the literature. Sustainability, 8(7), 691.

Carlson, R. (2016). Estimating the biotech sector's contribution to the US economy. Nature Biotechnology, 34(3), 247-255.

Chahrour, M., Assi, S., Bejjani, M., Nasrallah, A. A., Salhab, H., Fares, M., \& Khachfe, H. H. (2020). A bibliometric analysis of COVID-19 research activity: A call for increased output. Cureus, 12(3), e7357.

Devaney, L., \& Iles, A. (2019). Scales of progress, power and potential in the US bioeconomy. Journal of Cleaner Production, 233, 379-389.

Dietz, T., Börner, J., Förster, J. J., \& Von Braun, J. (2018). Governance of the bioeconomy: A global comparative study of national bioeconomy strategies. Sustainability, 10(9), 3190.

Doussoulin, J. P. (2020). COVID-19: Turning a threat into an opportunity for the circular economy. In T. Zhang (Ed.), Circular economy-Recent advances, new perspectives and applications.IntechOpen..

Doussoulin, J. P., \& Mougenot, B. (2021). The economic, climate change and public health edges of the geopolitics of COVID-19: An exploratory bibliometric analysis. In Biotechnology to combat COVID-19. 
IntechOpen. https://doi.org/10.5772/intechopen.96797. Available from: https://www.intechopen.com/ online-first/the-economic-climate-change-and-public-health-edges-of-the-geopolitics-of-covid-19-anexploratory-bi

El-Chichakli, B., von Braun, J., Lang, C., Barben, D., \& Philp, J. (2016). Policy: Five cornerstones of a global bioeconomy. Nature News, 535(7611), 221.

Elsevier. (2021). How Scopus works: Information about Scopus product features. Elsevier.com. Retrieved April 23, 2021, from https://www.elsevier.com/solutions/scopus/how-scopus-works

European Commission. (2012). Innovating for sustainable growth: A bioeconomy for Europe. European Commission..

European Commission. (2018a). A sustainable bioeconomy for Europe: Strengthening the connection between economy, society and the environment, update bioeconomy strategy. European Commission..

FAO. (2018). Assessing the contribution of bioeconomy to countries' economy. Retrieved April 30, 2021, from http://www.fao.org/3/I9580EN/i9580en.pdf

Fitzgerald, N. D. (2017). Chemistry challenges to enable a sustainable bioeconomy. Nature Reviews Chemistry, 1(10), 1-3.

Gagolewski, M. (2011). Bibliometric impact assessment with R and the CITAN package. Journal of Informetrics, 5(4), 678-692.

Georgescu-Roegen, N. (1971). The entropy law and the economic process. Harvard University Press..

Giampietro, M. (2019). On the circular bioeconomy and decoupling: Implications for sustainable growth. Ecological Economics, 162, 143-156.

Goebel, F.-R., \& Sallam, N. (2011). New pest threats for sugarcane in the new bioeconomy and how to manage them. Current Opinion in Environmental Sustainability, 3(1-2), 81-89.

Guo, M., \& Song, W. (2019). The growing US bioeconomy: Drivers, development and constraints. New Biotechnology, 49, 48-57.

Hagemann, N., Gawel, E., Purkus, A., Pannicke, N., \& Hauck, J. (2016). Possible futures towards a woodbased bioeconomy: A scenario analysis for Germany. Sustainability, 8(1), 98.

Haines, A. (2021). Health in the bioeconomy. The Lancet Planetary Health, 5(1), e4-e5.

Ikeda, K. (1979). Consumption and food utilization by individual larvae and the population of a wood borer Phymatodes maaki Kraatz (Coleoptera: Cerambycidae). Oecologia, 40(3), 287-298.

Imbert, E., Ladu, L., Morone, P., \& Quitzow, R. (2017). Comparing policy strategies for a transition to a bioeconomy in Europe: The case of Italy and Germany. Energy Research \& Social Science, 33, 70-81.

Khan, N., le Roes-Hill, M., Welz, P. J., Grandin, K. A., Kudanga, T., Van Dyk, J. S., Ohlhoff, C., Van Zyl, W. H., \& Pletschke, B. I. (2015). Fruit waste streams in South Africa and their potential role in developing a bio-economy. South African Journal of Science, 111(5-6), 1-11.

Labuto, G., \& Carrilho, E. (2016). Bioremediation in Brazil: Scope and challenges to boost up the bioeconomy. In M. N. V. Prasad (Ed.), Bioremediation and bioeconomy. (pp. 569-588). Elsevier..

Li, W., \& Zhao, Y. (2015). Bibliometric analysis of global environmental assessment research in a 20 -year period. Environmental Impact Assessment Review, 50, 158-166.

Louvel, R., \& de Gromard, C. (2017). From biomass to bioeconomics, an energy strategy for Africa? Afrique Contemporaine, 1, 223-240.

Mao, G., Huang, N., Chen, L., \& Wang, H. (2018). Research on biomass energy and environment from the past to the future: A bibliometric analysis. Science of the Total Environment, 635, 1081-1090.

McCormick, K., \& Kautto, N. (2013). The bioeconomy in Europe: An overview. Sustainability, 5(6), 2589-2608.

Mittra, J. (2015). The new health bioeconomy: $R \& D$ policy and innovation for the twenty-first century. Springer.

Moral-Muñoz, J. A., Herrera-Viedma, E., Santisteban-Espejo, A., \& Cobo, M. J. (2020). Software tools for conducting bibliometric analysis in science: An up-to-date review. El Profesional De La Información, 29(1), 4.

O’Hara, I. M., \& Glenn, D. (2017). The economic case for bioeconomy development in Australia. Industrial Biotechnology, 13(2), 65-68.

Organisation for Economic Cooperation and Development (OECD). (2009). The bioeconomy to 2030: Designing a policy agenda. OECD..

Rodríguez, A. G., Mondaini, A. O., \& Hitschfeld, M. A. (2017). Bioeconomía en América Latina y el Caribe: Contexto global y regional y perspectivas (No. 215). Naciones Unidas Comisión Económica para América Latina y el Caribe (CEPAL).

Ruiz-Real, J. L., Uribe-Toril, J., De Pablo Valenciano, J., \& Gázquez-Abad, J. C. (2018). Worldwide research on circular economy and environment: A bibliometric analysis. International Journal of Environmental Research and Public Health, 15(12), 2699. 
Sadhukhan, J., Martinez-Hernandez, E., Murphy, R. J., Ng, D. K., Hassim, M. H., \& NgKinJayeHangAndiappan, K. S. W. Y. I. F. M. Y. V. (2018). Role of bioenergy, biorefinery and bioeconomy in sustainable development: Strategic pathways for Malaysia. Renewable and Sustainable Energy Reviews, 81, 1966-1987.

Saikia, K., Vallès, M., Fabregat, A., Saez, R., \& Boer, D. (2020). A bibliometric analysis of trends in solar cooling technology. Solar Energy, 199, 100-114.

Sasson, A., \& Malpica, C. (2018). Bioeconomy in Latin America. New Biotechnology, 40, 40-45.

Schaltegger, S., Gibassier, D., \& Zvezdov, D. (2013). Is environmental management accounting a discipline? A bibliometric literature review. Meditari Accountancy Research, 21(1), 4-31.

Schmidt, O., Padel, S., \& Levidow, L. (2012). The bio-economy concept and knowledge base in a public goods and farmer perspective. Bio-Based and Applied Economics, 1(1), 47-63.

Staffas, L., Gustavsson, M., \& McCormick, K. (2013). Strategies and policies for the bioeconomy and biobased economy: An analysis of official national approaches. Sustainability, 5(6), 2751-2769. https:// doi.org/10.3390/su5062751

Trigo, E. J., Henry, G., Sanders, J. P. M., Schurr, U., Ingelbrecht, I., Revell, C., Santana, C., \& Rocha, P. (2015). Towards bioeconomy development in Latin America and the Caribbean. In E. Hodson (Ed.), Towards a Latin America and Caribbean knowledge based bio-economy in partnership with Europe. (pp. 15-41). Pontificia Universidad Javeriana..

van Meijl, H., Tsiropoulos, I., Bartelings, H., Hoefnagels, R., Smeets, E., Tabeau, A., \& Faaij, A. (2018). On the macro-economic impact of bioenergy and biochemical-Introducing advanced bioeconomy sectors into an economic modelling framework with a case study for the Netherlands. Biomass and Bioenergy, $108,381-397$.

Van Renssen, S. (2014). A bioeconomy to fight climate change. Nature Publishing Group..

Virgin, I., \& Morris, E. J. (2016). Creating sustainable bioeconomies: The bioscience revolution in Europe and Africa. Taylor \& Francis..

Vivien, F.-D., Nieddu, M., Befort, N., Debref, R., \& Giampietro, M. (2019). The hijacking of the bioeconomy. Ecological Economics, 159, 189-197.

White House. (2012). National bioeconomy blueprint. The White House..

Zhai, F., Zhai, Y., Cong, C., Song, T., Xiang, R., Feng, T., Liang, Z., Zeng, Y., Yang, J., Yang, J., \& Liang, J. (2020). Research progress of coronavirus based on bibliometric analysis. International Journal of Environmental Research and Public Health, 17(11), 3766.

Publisher's Note Springer Nature remains neutral with regard to jurisdictional claims in published maps and institutional affiliations. 